\title{
Acidification of Deionized Water by Roots of Intact Rice Seedlings
}

\author{
Sheng Lee Chen, Chien Teh Chen and Ching Huei Kao
}

\author{
Department of Agronomy, National Taiwan University, Taipei, Taiwan, Republic of China
}

\begin{abstract}
This investigation was designed to examine whether or not deionized water could be acidified by roots of intact rice seedlings. Roots of intact rice seedlings caused significant acidification of the deionized water in which they were immersed and this acidification could be repeated after replacement of acidified water with fresh deionized water. The addition of $\mathrm{K}^{+}, \mathrm{Na}^{+}$, and $\mathrm{Mg}^{2+}$ to the deionized water significantly increased the rate and extent of acidification. However, no such increase was found when $\mathrm{Ca}^{2+}$ was present in the water. The inhibition of acidification by vanadate and its promotion by fusicoccin indicated that the acidification of water by roots of intact rice seedlings originated from an ATP-driven proton pump located in the plasmalemma.

Ferricyanide was effectively reduced by the roots of intact rice seedlings. This reduction was associated with the acidification of the bathing solution. 8-Hydroxyquinoline and $p$-nitrophenylacetate inhibited both the reduction of ferricyanide and ferricyanide-induced acidification. Vanadate, although it slightly inhibited the reduction of ferricyanide, did not inhibit the ferricyanide-stimulated decrease in $\mathrm{pH}$. It seems that the involvement of redox activity associated with the plasmalemma in the acidification of deionized water cannot be excluded.
\end{abstract}

Key words: Acidification - Oryza sativa - Root - Transmembrane redox activity.

It has long been recognized that the net release of protons by roots of intact plants is strongly dependent on the source of nitrogen that is supplied to plants; a supply of nitrogen as $\mathrm{NH}_{4}^{+}$results in a decrease in $\mathrm{pH}$ while a supply of nitrogen as nitrate results in a slight increase in $\mathrm{pH}$ of the nutrient solution (Kirby and Mengel 1967). Recently, Mengel and Malissiovas (1982) and Mengel and Schubert (1985) provided evidence that roots of intact Vitis and maize were capable acidifying deionized water and that this acidification is related to an ATPase associated with the plasmalemma. However, the $\mathrm{H}^{+}$-ATPase does not seem to be the only mediator of acidification by plant roots. Recent evidence suggests the existence of plasmalemma redox activity in plants. Plasmalemma redox activity has been shown to affect the extrusion of protons by isolated roots and root protoplasts (Federico and Giartosio 1983, Lin 1984, Rubinstein and Stern 1986, Sijmons et al. 1984) but not by roots of intact plants.

The results presented in this communication demonstrate that roots of rice seedlings are able to acidify deionized water. Evidence is also provided to show that this

Abbreviations: ATPase, adenosine triphosphatase; $8 \mathrm{HQ}, 8-$ hyroxyquinoline; pNPA, p-nitrophenylacetate; Tris- $\mathrm{HCl}$, tris(hydroxymethyl)-aminomethane $\mathrm{HCl}$. acidification is coupled to ATPase and redox activity that is associated with the plasmalemma.

\section{Materials and Methods}

Rice (Oryza sativa L. cv. Taichung Native 1) seedlings were cultured as previously described (Cheng and Kao 1986). Briefly, seedlings were planted on a stainless steel net floating on half-strength Johnson's modified nutrient solution (Johnson et al. 1957) in a $500-\mathrm{ml}$ beaker. The nutrient solution ( $\mathrm{pH}$ 4.8) was replaced every three days. Rice seedlings were grown in a green-house with natural daylight at $30^{\circ} \mathrm{C}$ by day $25^{\circ} \mathrm{C}$ by night. All experiments were carried out with seedlings at the 4-leaf stage, 12 days after planting, when the third leaves were fully expanded. Each treatment contained three replicates.

Acidification of deionized water by roots of intact rice seedlings was monitored by measuring the changes in $\mathrm{pH}$ of the water. There were only minute quantities of ions present in deionized water. In order to avoid contamination by cations from the nutrient solution, roots were thoroughly washed with deionized water prior to use in the various experiments. For an examination of the acidification of deionized water by roots, three seedlings were placed separately in $100-\mathrm{ml}$ beakers that contained $50 \mathrm{ml}$ of 
deionized water. Each beaker was wrapped in aluminum foil with the top left uncovered. Since rice plants are adapted to flood conditions, no aeration was applied to the outer solution throughout the experiments. Beakers were then placed in a growth chamber at a controlled temperature of $27^{\circ} \mathrm{C}$ and a light intensity of $20 \mathrm{~W} \cdot \mathrm{m}^{-2}$ provided by fluorescent lamps. The $\mathrm{pH}$ after various intervals was determined with a $\mathrm{pH}$ meter.

The reduction of ferricyanide was examined by the method of Federico and Giartosio (1983). Roots of three seedlings were incubated separately in $5 \mathrm{ml}$ of $1 \mathrm{mM}$ Tris$\mathrm{HCl}$ (pH 7.0) that contained $0.5 \mathrm{mM} \mathrm{CaCl}_{2}, 50 \mathrm{mM} \mathrm{KCl}$ and $0.8 \mathrm{mM}$ potassium ferricyanide plus $0.8 \mathrm{mM}$ 8-hydroxyquinoline or $0.1 \mathrm{~mm} p$-nitrophenylacetate as indicated below. The temperature was maintained at $27^{\circ} \mathrm{C}$. The reaction was monitored by following the decrease in absorbance of the solution at $420 \mathrm{~nm}$.

\section{Results and Discussion}

From the agricultural and ecological point of view, root-induced acidification of the soil/root interface (rhizosphere) is an important mechanism for the mobilization of plant nutrients from soil that is initially devoid of soluble nutrients. Thus, it would be of great interest if we could ascertain whether roots of intact plants can secret protons into the soil without a concomitant net uptake of $\mathrm{K}^{+}$or other species of cation. To simulate the conditions found in soil without soluble nutrients, deionized water was used as the bathing medium in an investigation of the capacity of the roots of intact rice seedlings to excrete protons. The decrease in $\mathrm{pH}$ of deionized water by roots of rice seedlings is shown in Figure 1. Roots of seedlings decreased the $\mathrm{pH}$ of deionized water from 5.8 to 5.2 within two hours. The decrease in the $\mathrm{pH}$ was rapid and was detectable within 15 minutes. Since no significant changes in $\mathrm{pH}$ were observed in deionized water without plants, the decrease in the $\mathrm{pH}$ of deionized water by roots of rice seedlings was attributed to the roots. The decrease in the $\mathrm{pH}$ of deionized water could be repeated by changing the bathing medium to fresh deionized water. The results presented in Figure 1 were reproducible and in agreement with results reported by Mengel and Schubert (1985), who used intact maize plants.

The effects of $\mathrm{KCl}, \mathrm{NaCl}, \mathrm{CaCl}_{2}$ and $\mathrm{MgCl}_{2}$ in the

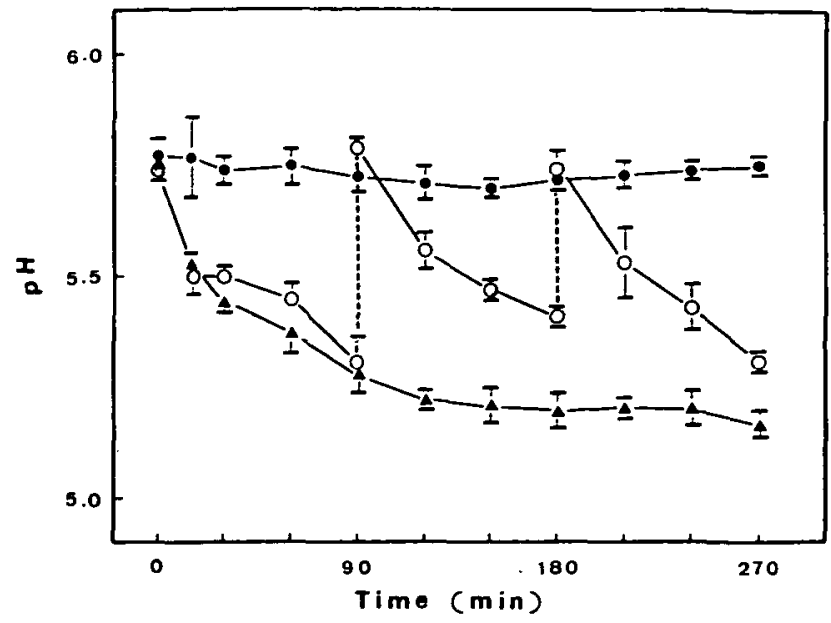

Fig. 1 Decrease in the $\mathrm{pH}$ of deionized water by roots of intact rice seedlings. $(\bullet)$, Deionized water without plants; ( $\Lambda$ ), continuous deionized water supply; $(O)$, deionized water replaced at intervals of $90 \mathrm{~min}$.

outer solution on the acidification by roots of intact rice seedlings are shown in Table 1 . Compared to deionized water alone, water supplemented with $\mathrm{K}^{+}, \mathrm{Na}^{+}$and $\mathrm{Mg}^{2+}$ was associated with significant increase in the rate and extent of the acidification. In contrast to the results of Mengel and Schubert (1985), we found that $\mathrm{Ca}^{2+}$ did not increase the acidification of the bathing medium by roots of rice seedlings. The use of different plant materials may be responsible for this discrepancy.

The stimulation of acidification by various species of cation $\left(\mathrm{K}^{+}, \mathrm{Na}^{+}\right.$, and $\left.\mathrm{Mg}^{2+}\right)$ can be explained in terms of a $\mathrm{H}^{+} /$cation antiporter. Since acidification was also observed in the absence uptake of cations (Fig. 1), ATPase activity is probably associated with the $\mathrm{H}^{+}$/cation exchange. In a system of root in deionized water, $\mathrm{K}^{+}$released from the cytoplasm into the free space of the roots will be reabsorbed and therefore, drive a $\mathrm{H}^{+} / \mathrm{K}$ antiport. However, such a mechanism can not explain the promotive effects of $\mathrm{Na}^{+}$and $\mathrm{Mg}^{2+}$ on acidification. Our results do not exclude such an antiport but, since $\mathrm{Na}^{+}$and $\mathrm{Mg}^{2+}$ also increased the rate and extent of acidification significantly, its involvement seems unlikely.

Figure 2 shows that that the decrease in the $\mathrm{pH}$ of the

Table 1 Effects of metal chlorides in the bathing solution on the change in $\mathrm{pH}$ caused by roots of intact rice seedlings

\begin{tabular}{lccccc}
\hline Outer solution & Water & $\mathrm{KCl}$ & $\mathrm{NaCl}$ & $\mathrm{CaCl}_{2}$ & $\mathrm{MgCl}_{2}$ \\
\hline$-\Delta \mathrm{pH}$ & $0.73 \pm 0.01$ & $1.26 \pm 0.11$ & $1.10 \pm 0.10$ & $0.72 \pm 0.06$ & $0.93 \pm 0.13$
\end{tabular}

The concentration of chloride ions was $5 \mathrm{~mm}$. Roots were incubated in each solution for $3 \mathrm{~h} . \quad-\Delta \mathrm{pH}=-($ final $\mathrm{pH}-\mathrm{initial} \mathrm{pH})$. 


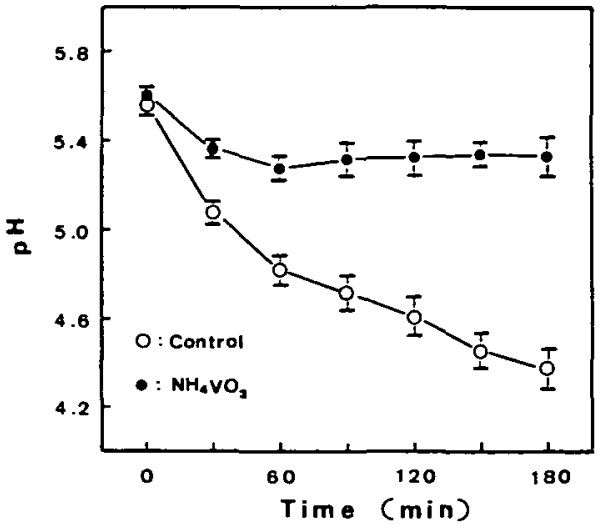

Fig. 2 Effects of vanadate on the $\mathrm{pH}$ of the outer solution. The control bathing solution contained $0.1 \mathrm{~mm} \mathrm{KH}_{2} \mathrm{PO}_{4}$ and $0.5 \mathrm{mM} \mathrm{NH} \mathrm{N}_{4} \mathrm{Cl}$. The experimental solution contained $0.5 \mathrm{~mm}$ $\mathrm{NH}_{4} \mathrm{VO}_{3}$ and $0.1 \mathrm{~mm} \mathrm{KCl}$.

outer medium by rice seedlings was significantly inhibited by vanadate $(0.5 \mathrm{~mm})$. It should be noted that this effect could not be attributed to the buffering capacity of vanadate since the control included phosphate buffer. Fusicoccin $(10 \mu \mathrm{M})$, by contrast, promoted the decrease in pH caused by roots of rice seedlings (Fig. 3). Vanadate inhibits the plasmalemma-associated ATPase, and fusicoccin has a promotive effect on the plasmalemma ATPase (Marrè 1979, Rea and Sanders 1987). Since the effect of vanadate is rapid, it is likely that, under our conditions, vanadate is acting primarily as an inhibitor of the plasmalemma ATP. ase. Our data seem to support the conclusion that the acidification of deionized water by roots of intact rice seedlings originates from an ATP-driven proton pump located in the plasmalemma.

Ferricyanide does not permeate into the roots of intact

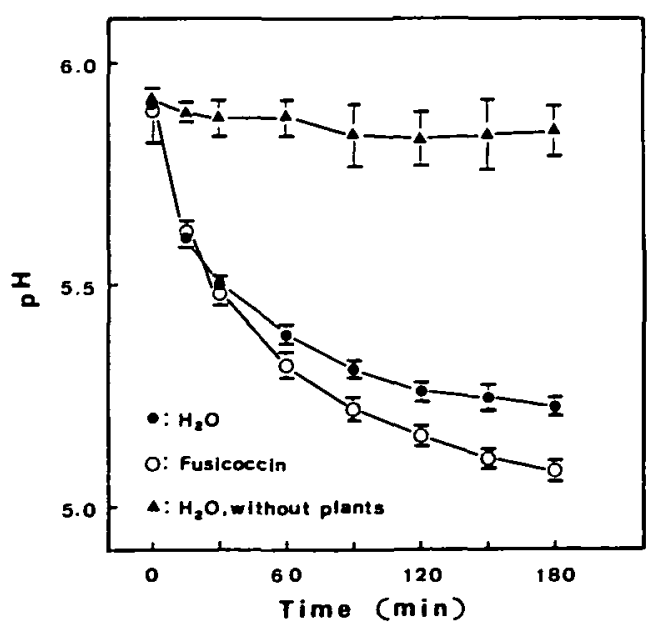

Fig. 3 Effects of fusicoccin on the $\mathrm{pH}$ of the outer solution. The concentration of fusicoccin was $10 \mu \mathrm{M}$. rice seedlings. However, such roots reduced external ferricyanide, utilizing endogenous substrate, at a constant rate for $210 \mathrm{~min}$ (Fig. 4). It has been shown that the reduction of ferricyanide is functionally related to the release of protons (Federico and Giartosio 1983, Kochian and Lucas 1985, Lin 1984, Rubinstein and Stern 1986). Our data also show that ferricyanide significantly promoted the decrease in pH caused by roots of intact rice seedlings (Fig. 4). Our observations suggest the existence of transmembrane redox activity in roots of intact rice seedlings. This conclusion is further supported by the observation that that potassium ferrocyanide had no effect acidification (data not shown). The inactivity in this respect of potassium ferrocyanide also illustrates the fact that the action of potassium ferricyanide is not related to the presence of potassium. $p-\mathrm{Ni}$ trophenylacetate inhibits the NADH-ferricyanide oxido-reductase activity of the plasma membrane (Morrè et al. 1988), while 8-hydroxyquinoline inhibits electron-transport reactions in the plasmalemma (Barr 1988). If the transmembrane redox system is involved in the acidification of deionized water by roots of intact rice seedlings,

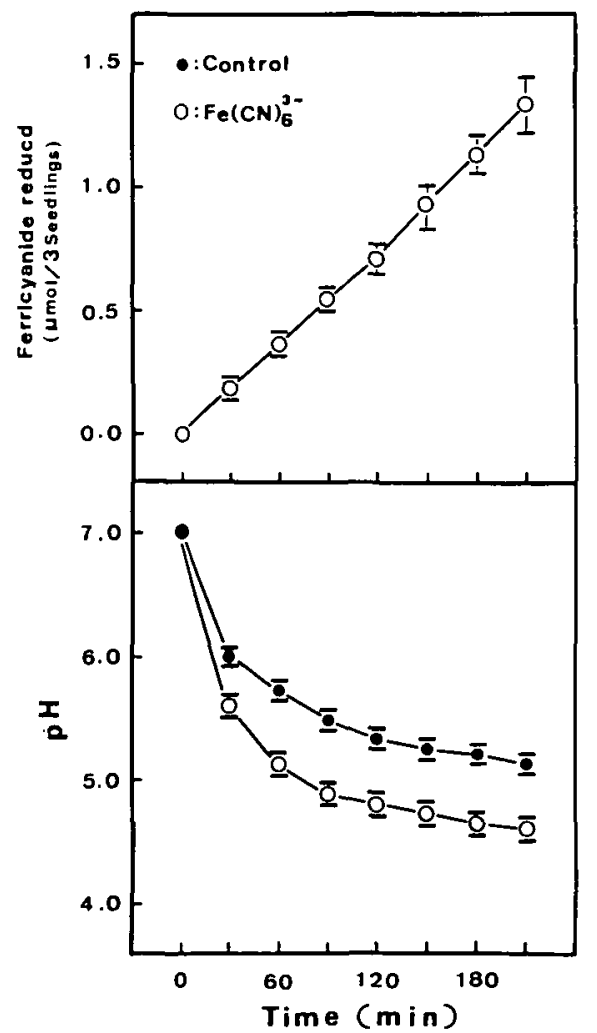

Fig. 4 Reduction of ferricyanide by roots of rice seedlings and the effects of ferricyanide on the $\mathrm{pH}$ of the outer solution. For the measurement of $\mathrm{pH}$, roots of three rice seedlings were in cubated separately in $5 \mathrm{ml}$ of $1 \mathrm{mM}$ Tris- $\mathrm{HCl}(\mathrm{pH} \mathrm{7.0})$, that contained $0.5 \mathrm{mM} \mathrm{CaCl}$ and $50 \mathrm{mM} \mathrm{KCl}$, with or without $0.8 \mathrm{~mm}$ potassium ferricyanide. 
then both inhibitors would be expected also to inhibit the acidification caused by ferricyanide and the reduction of the ferricyanide. As shown in Figure 5, this is indeed the case.

If the decrease in $\mathrm{pH}$ in response to the presence of ferricyanide represents the release of protons, it becomes important to determine whether redox activity provides a pathway for the passage of protons across the plasma membrane in addition to, and independent of, the pathway that is usually associated with a $\mathrm{H}^{+}$-ATPase. If acidification in response to ferricyanide is associated with a $\mathrm{H}^{+}$-ATPase, vanadate would be expected to inhibit acidification. As indicated in Figure 6, such is not the case. Vanadate, although it slightly inhibited the reduction of ferricyanide, did not inhibit the ferricyanide-stimulated acidification. Our result are inconsistent with those reports by other workers, who found that various inhibitors of ATPase activity inhibited the ferricyanide-stimulated transport of protons (Romheld et al. 1984, Rubinstein and Stern 1986). It seems that the channel for the redox-induced movement of protons may be different from that for the ATP-dependent release of protons. The slight inhibition of the reduction of ferricyanide by vanadate may possibly be due to the effect of vanadate on the availability of the electron donor or some other, nonspecific effect.

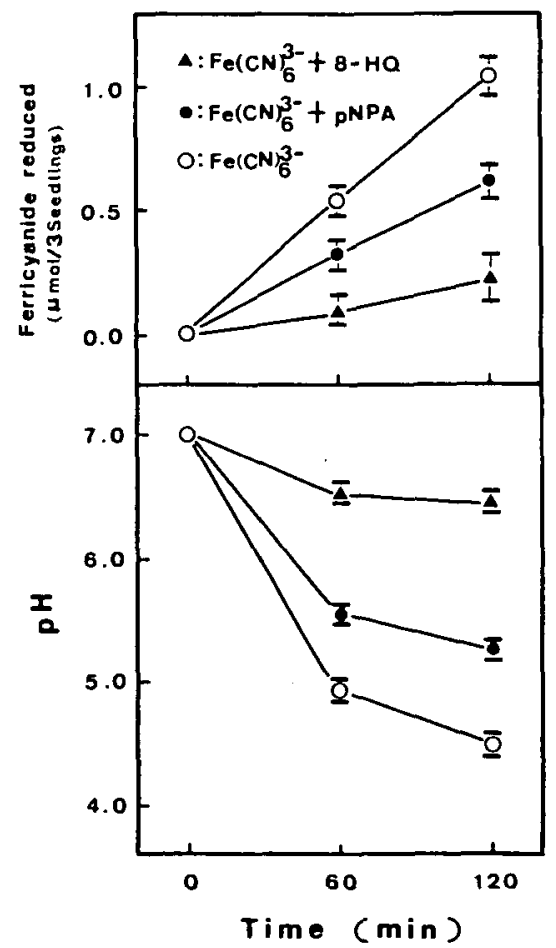

Fig. 5 Effects of 8-hydroxyquinoline (8-HQ) and p-nitrophenylacetate ( $\mathrm{pNPA}$ ) on the $\mathrm{pH}$ of the outer solution and the reduction of ferricyanide. The concentrations of 8-HQ and pNPA were $0.8 \mathrm{~mm}$ and $0.1 \mathrm{~mm}$, respectively.
If a separate pathway for the release of protons does exist, one might expect a fixed stoichiometry of ferricyanide-stimulated release of protons and the reduction of ferricyanide. As indicated in Figures 4 and 6, the reduction of ferricyanide proceeded linearly with time. However, the $\mathrm{pH}$ decreased rapidly within $60 \mathrm{~min}$ after the addition of ferricyanide, and no subsequent decrease in $\mathrm{pH}$ was observed. Thus, it is possible that the redox activity after $60 \mathrm{~min}$, as measured here, involves exclusively the transport of electrons across the plasmalemma. It seems that the association of the transmembrane transport of electron with the release of protons only operates during the early phase of the incubation. It should be noted, in this context, that acidification of deionized water, as shown in Figure 1, also occurred during the early phase of the incubation.

The ferricyanide used in our experiments is an impermeable oxidant, and it serves as an artificial probe for the transmembrane transport of electrons. The natural oxidants may be ions, such as ferric ions, which must be reduced before they enter the cell in a reduced state (Bienfait

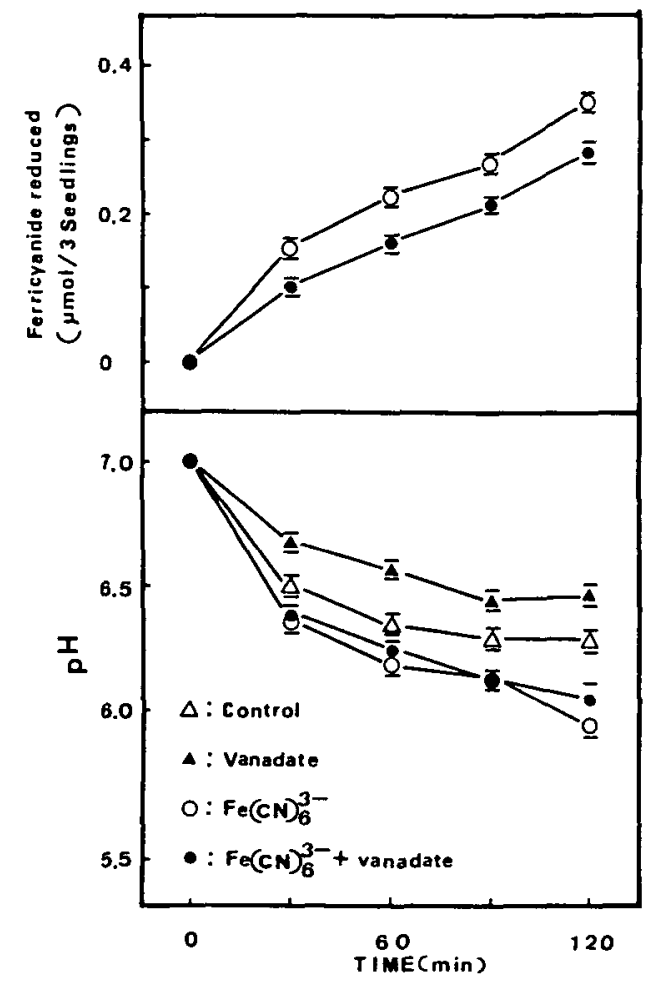

Fig. 6 Effects of vanadate on the reduction of ferricyanide and on the ferricyanide-stimulated acidification by roots of rice seedlings. Roots of three rice seedlings were incubated separately in $5 \mathrm{ml}$ of $1 \mathrm{~ms}$ Tris- $\mathrm{HCl}(\mathrm{pH} 7.0)$ that contained $0.5 \mathrm{mM} \mathrm{CaCl}$, $50 \mathrm{~mm} \mathrm{KCl}$ and $0.5 \mathrm{mM} \mathrm{NH}{ }_{4} \mathrm{Cl}$, with or without $0.8 \mathrm{~mm}$ potassium ferricyanide. The concentration of vanadate $\left(\mathrm{NH}_{4} \mathrm{VO}_{3}\right)$ was $0.5 \mathrm{~mm}$. 
1985, Brown 1978) and oxygen. Rice plants are frequently grown on flooded soil. Ferric ions can undergo reduction in flooded soil. Although the reduction of ferric ions is important for providing enough $\mathrm{Fe}^{2+}$ to meet the nutritional requirements of rice plants, $\mathrm{Fe}^{2+}$ does not seem to be lacking in flooded soils. It has been shown that iron-deficient plants develop a high capacity for the reduction of ferric ion at the root surface (Brown 1978). Under natural conditions, ferric ion is unlikely to serve as an oxidant for the transmembrane transport of electrons and, thus, transmembrane redox activity would be less important than plasmalemma-located ATPase activity with respect to acidification of the external medium in which the rice plants are growing. Root-induced acidification most probably plays an important role in the mobilization of nutrients from soil that is initially devoid of soluble nutrients.

This work was supported by the National Science Council, Republic of China under Grant NSC78-0414-C002-01.

\section{References}

Barr, R. (1988) The effect of inhibitors of plasma membrane redox reactions on proton excretion by plant cells. Physiol. Plant. 73: 194-199.

Bienfait, H. F. (1985) Required redox processes at the plasmalemm of plant root cells and their function in iron uptake. J. Bioenerg. Biomemb. 17: 73-83.

Brown, J. C. (1978) Mechanism of iron uptake by plants. Plant Cell Environ. 1: 249-257.

Cheng, S. H. and Kao, C. H. (1984) The role of proteolytic enzymes in protein degradation during senescence of rice leaves. Physiol. Plant. 62: 231-237.

Federico, R. and Giartosio, C. E. (1983) A transplasma membrane electron transport system in maize roots. Plant Physiol.
73: 182-184.

Johnson, C. M., Stout, P. R., Broyer, T. C. and Carlton, A. B. (1957) Comparative chlorine requirements of different plant species. Plant Soil 8: 337-353.

Kirby, E. A. and Mengel, K. (1967) Ionic balance in different tissues of the tomato plant in relation to nitrate, urea or ammonium nutrition. Plant Physiol. 42: 6-14.

Kochian, L. V. and Lucas, W. J. (1985) Potassium transport in corn roots. III. Perturbation by exogenous NADH and ferricyanide. Plant Physiol. 77: 429-436.

Lin, W. (1984) Further characterization on the transport property of plasmalemma NADH oxidation system in isolated root protoplasts. Plant Physiol. 74: 219-222.

Marrè, E. (1979) Fusicoccin: a tool in plant physiology. Annu. Rev. Plant Physiol. 30: 273-288.

Mengel, K. and Malissiovas, N. (1982) Light-dependent proton secretion by roots of entire plants (Vitis vinifera L.). $Z$. Pflanzenernahr Bodenk 145: 261-267.

Mengel, K. and Schubert, S. (1985) Active extrusion of protons into deionized water by roots of intact maize plants. Plant Physiol. 79: 344-348.

Morre, D. J., Crane, F. L., Barr, R., Penel, C. and Wu, L.-Y. (1988) Inhibition of plasma membrane redox activities and elongation growth of soybean. Physiol. Plant. 72: 236-240.

Rea, P. H. and Sanders, D. (1987) Tonoplast energization: two $\mathrm{H}^{+}$pumps, one membrane. Physiol. Plant. 71: 131-141.

Romheld, V., Muller, C. and Marschner, H. (1984) Localization and capacity of proton pumps in roots of intact sunflower plants. Plant Physiol. 76: 603-606.

Rubinstein, B. and Stern, A. I. (1986) Relationship of transplasmalemma redox activity to proton and solute transport by roots of Zea mays. Plant Physiol. 80: 805-811.

Sijmons, P. D., Van den Briei, W. and Bienfait, H. F. (1984) Cytosolic NADPH is the electron donor for extracellular Fe III reduction in iron-deficient bean roots. Plant Physiol. 75: 219221. 
